\section{OVULATION AND MENSTRUATION}

BY

WILFRED SHAW, M.D., F.R.C.S., F.C.O.G.

ASSISTANT PHYSICIAN-ACCOUCHEUR, ST. BARTHOLOMEW'S HOSPITAL

Relatively few contributions have been made in recent years to the study of the time relations between ovulation and menstruation in the human female. The work of Robert Meyer, ${ }^{1}$ Robert Meyer and Ruge, ${ }^{2}$ Schröder, ${ }^{3}$ and Novak $^{4}$ indicated that ovulation was restricted to the intermenstrual phase. In $1925 \mathrm{I}^{12}$ published some observations of my own which furnished additional evidence in support of this view. Since then publications have attacked the problem indirectly: some have supported the view expressed above, others have opposed it. As a result much confusion exists at the present time, and I have thought that an examination of the material collected since 1925 might help to clear up some of the difficulties which have arisen. There has perhaps been a tendency in recent years to attach too much importance to formulating a parallel between the sex cycles of man and the lower animals. When the results of gynaecologists have not agreed with the interpretations of animal workers experimentalists have sometimes been apt to dismiss the gynaecological point of view with scant respect. An attempt will be made below to restrict the observations and interpretations to the human material, and not to be unduly influenced by the results of animal work. Homologies and such-like excursions can conveniently be left to the biologists.

The normal menstrual cycle is regarded as one of twentyeight days: the first day of the period of bleeding is taken as the first day of the cycle. The phases of the menstrual cycle ane referred to in terms of the particular day after the first day of the last period.

Schröder has pointed out that the following methods are available to investigate the time relations.

1. The inspection of ovaries during abdominal operations. Fraenkel originally employed this method and gave a wide -variation between the tenth and twenty-fourth days of the cycle. The method is not capable of great precision, and having examined ovaries carefully for ten years I am still unable to distinguish between ripening follicles and recently ruptured follicles by naked-eye examination alone.

2.'The determination of the onset of Mittelschmerz. This method is unreliable, and personally I do not believe that Mittelschmerz is caused in-all cases by the rupture of a follicle.

3. One of the most trustworthy methods is the demonstration by histological means of a recently ruptured follicle in accurately dated material. Post-mortem material is of little if any value, partly because it is rarely accurately dated, and partly because its histology is often difficult.

4. This method is indirect and is based upon the conception that the secretory phase of the endometrium develops immediately after ovulation. The histological appearances of the endometrium during the secretory phase are specific. If they can be demonstrated in the endometrium it is assumed that ovulation has taken place previously.

5. Some evidence can be obtained from the determination of the intensity of the circulating sex hormones in the blood at different stages of the menstrual cycle.

6. The most convincing of all methods is the demonstration of ova in washings from the Fallopian tube. Allen, ${ }^{5}$ using this method, has shown that ovulation is restricted to about the fourteenth day of the cycle.

Schröder, who has collected more accurately dated material than anyone else, maintains that the time of ovulation is constant during the menstrual cycle of regularly menstruating women, except perhaps for very rare exceptions. At the other extreme is Grosser, who still believes that ovulation depends to a great degree upon cohabitation.
IMPORTANCE OF ACCURATELY DATED MATERIAL

Schröder has pointed out that many of the discrepancies in the published work on the determination of the time of ovulation depend upon the use of material which is not accurately dated. It should be remembered that Krieger and Fosten ${ }^{6}$ have shown that a menstrual cycle of twentyeight days is present only in 60 per cent. of women. Similar figures are given by Hajek ( 56 per cent.) and Weinstock (58 per cent.). It is obvious that care must b3 taken in comparing the time of ovulation in a twentyeight-day cycle with the results found in a cycle of twenty-one days. In a paper on irregular uterine haemorrhage, published in $1929,{ }^{13}$ I showed that when the cycle is reduced ovulation occurs much earlier than the accepted fourteenth day. Similar observations have been made by Ogino, who demonstrated that the constant factor for all menstrual cycles is the time between ovulation and the succeeding period. In the present contribution $I$ have restricted the material to cases with twenty-eight-day cycles.

\section{Material in Present Investigation}

The specimens have been obtained by operation for such gynaecological conditions as fibroids and myohyperplasia. In all cases data have been available as to $(a)$ the first day of the last menstrual period, $(b)$ the date of the operation, and $(c)$ the normal cycle for the patient concerned. I have taken great pains to collect accurate data, and have rejected all cases in which the details were not precise. It is frequently found that patients are unable to remember exactly. when their last period began. It is also remarkable how many women have cycles departing by a day or two from a strict twenty-eight-day cycle who maintain that their cycle is regular for twenty-eight days, until they are closely questioned. I have observed thirty-six cases in which the ovaries have been examined from patients with accurate menstrual histories. In addition I have collected forty-nine cases in which the uterus alone was removed. In twenty-one of the patients in whom the ovaries were examined the uterus was also investigated histologically. The material therefore consists of thirty-six cases in which the cyclical changes in the ovaries could be examined, and seventy in which the cyclical variations of the endometrium could be studied.

\section{OVARIAN GROUP}

Thirty-six cases belong to this group. The specimens are dated as follows:

\begin{tabular}{|c|c|c|c|}
\hline Day of Cycle & No. of Cases & & \\
\hline 1 & 1 & \multicolumn{2}{|c|}{ Retrogressing corpus luteum } \\
\hline 2 & 2 & & " \\
\hline 8. & 1 & & " \\
\hline 9 & 1 & & 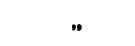 \\
\hline 10 & 1 & & $"$ \\
\hline 13 & 4 & \multicolumn{2}{|c|}{ Recently ruptured follicles } \\
\hline 15 & 3 & \multirow{2}{*}{\multicolumn{2}{|c|}{$\begin{array}{l}\text { Two recently ruptured follicl } \\
\text { One young corpus luteum } \\
\text { Young corpus luteum }\end{array}$}} \\
\hline 16 & 1 & & \\
\hline 17 & 8 & \multicolumn{2}{|c|}{ Early corpus luteum } \\
\hline 18 & 2 & \multicolumn{2}{|c|}{ Immature corpus luteum } \\
\hline 19 & 2 & $"$ & $\because$ \\
\hline 20 & 1 & ” & $"$ \\
\hline 21 & 2 & \multicolumn{2}{|c|}{ Mature corpus luteum } \\
\hline 22 & 3 & $"$ & $\cdots$ \\
\hline 24 & 1 & $"$ & $"$ \\
\hline 25 & 2 & $"$ & $"$ \\
\hline 26 & 1 & $"$ & 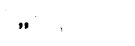 \\
\hline
\end{tabular}


Trme of Ovulation

I will describe first the ovarian material. There were thirty-six cases in all. Six specimens of a recently rupturer follicle were secured: the classical signs of a recent rupture were found in all; there was extreme haemorrhage in the theca interna layer, and the granulosa cells were both proliferating and undergoing hypertrophy. The corpus luteu 1 convolutions had not as yet formed. Four specimens were obtained on the thirteenth day and two on the fifteenth day of the cycle. These six specimens of recently ruptured follicle support the view that ovulation had taken place some time about the fourteenth day of the menstrual cycle. It is impossible to state how rapidly the ruptured follicle proliferates, and consequently one could not deduce exactly when ovulation had taken place. There are some grounds for believing that growth is extremely rapid, for the proliferation of a young corpus luteum about the seventeenth day of the cycle can be traced more accurately when it is found that after the twentieth day of the cycle the corpus luteum is fully developed. If, therefore, it takes only a few days for the corpus luteum to attain full maturity, it is reasonable to assume that the growth of a recently ruptured follicle is very rapid. For these reasons I believe that the six specimens of recently ruptured follicle were obtained soon after ovulation, and the demonstration of these offers direct evidence that ovulation is restricted to about the fourteenth day of the cycle.

The series examined does much more than this. The other cases, though not affording direct proof, indirectly favour this view. For example, in all specimens after the thirteenth day, thirty cases in all, there was none in which the ovaries did not contain either a recently ruptured follicle, a proliferating corpus luteum, or a mature corpus luteum. The later in the cycle that the specimen $v$ as removed the more mature was the corpus luteum. Proliferating corpora lutea were found, particularly about the seventeenth day. Lastly, in specimens observed in the early part of the cycle no recently ruptured follicles were found, and the corpora lutea detected in the ovaries were retrogressing. I wish to emphasize that the series is important, not merely because of the six specimens of recently ruptured follicle, but because the others circumstantially endorse the opinion that ovulation is restricted to about the fourteenth day.

\section{Is Time of Ovulation Constant?}

The series of specimens show that ovulation is restricted to about the fourteenth day of the menstrual cycle. On the other hand the samples of recently ruptured follicle indicate quite clearly that there is a little variation in the ovulation time. For example, one of the two recently ruptured follicles removed on the fifteenth day was younger than any of those of the thirteenth day. Similarly, in the specimens of the thirteenth day there were different degrees of development. Th:s implies that ovulation cannot be regarded as occurring always at a fixed time with all regularly menstruating women, and that there is a variation of at least two days in the ovulation time. Personally, I have no objection to postulating a parallel to the variations which Hartmann ${ }^{7}$ has found in the ovulation times of his colony of macaque monkeys. It is probable, however, that a departure of more than two days from the fourteenth day of the cycle is hardly ever, if ever, seen in the human subject. A further point should be borne in mind. However accurate the history, there is always a possibility of a little margin of error in the determination of the ovulation time. For example, a patient may start menstruating late one evening and the operation which leads to the demonstration of a recently ruptured follicle be performed early one morning. In such a case there is a margin of error of twelve hours in timing the specimen, and with two extreme cases of this kind a margin of twenty-four hours can be expected.
Evidence Against the Acćepted Teaching

Well-authenticated cases are on record in which no corpus luteum has been found post mortem in the ovaries of women who have been menstruating regularly. Examples are given by Teacher $^{8}$ and by Corner. ${ }^{9}$ It is not uncommon for patients who are desperately ill to cease menstruating shortly before death, and amenorrhoea of this kind is not infrequent. It is probably very exceptional to find no corpora lutea in the ovaries of women who have menstruated regularly, and such cases should be looked upon as pathological. The series which $I$ have just described illustrates that regular ovulation can be demonstrated in the ovaries of women with normal menstrual cycles.

Embryologists maintain that ovulation can be "provoked " by coitus, for it is sometimes difficult to admit that an early human ovum can attain its size in the short time available if ovulation is limited to about the fourteenth day of the cycle. Similarly, cases are recorded in the German literature in which pregnancy has followed a single coitus in the post-menstrual phase. My own view of these cases is that they can be explained in ways other than by assuming an alteration in the time of ovulation. If ovulation can be "provoked" by coitus one would have expected to find evidence of aberrant ovulation in such a series of specimens as I have described above. It is clearly impossible to deny that ovulation can be " provoked " by coitus : all that can be said is that, if it does occur, it is very exceptional.

Animal workers have sometimes been inclined to discredit the observations of gynaecologists on the time relations between ovulation and menstruation, in view of Corner's work on macaque monkeys. Corner has observed that macaque monkeys may develop cyclical uterine haemorrhage without ovulating, and it has even been suggested that menstruation in women may be comparable to this form of uterine bleeding. I shall show later, when dealing with specimens of the endometrium, that menstruation consists essent:ally of the degeneration and disintegration of a premenstrual endometrium. I have always admitted the possibility of uterine bleeding occurring in dependently of ovulation, but such cases should be looked upon as pathological. Cases of metropathia haemorrhagica afford the best example of this type of uterine bleeding. As I have already pointed out, I have always found evidence in my material that cyclical uterine bleeding in healthy women is accompanied by ovulation, and in consequence believe that ovulation should be regarded as form. ing an essential part of the sex cycle of women.

The Cyclical Changes in the Endometrium Seventy specimens of the endometrium were examined. The material cons:sted of sections through the thickness of the uterus, and included both endometrium and myometrium. The seventy specimens were accurately dated as follows:

\begin{tabular}{c|c|c|c}
\hline Day & No. of Specimens & Day & No. of Specimens \\
\hline 1 & 4 & 15 & 1 \\
2 & 7 & 16 & 1 \\
3 & 7 & 17 & 7 \\
4 & 1 & 18 & 2 \\
5 & 2 & 19 & 4 \\
8 & 1 & 20 & 2 \\
9 & 4 & 21 & 3 \\
10 & 4 & 22 & 1 \\
11 & 1 & 23 & 1 \\
12 & 1 & 24 & 3 \\
13 & 8 & 23 & 3 \\
\hline
\end{tabular}


A detailed description of the variations in histological structure during the menstrual cycle is beyond the scope of this contribution. Certain features, however, require emphasis. Examination of the endometrium always reveals a division into two zones, basal and functional. The basal layer, lying adjacent to the myometrium, takes little part in the cyclical alterations. It will be remembered that the proliferative phase consists of a diffuse hypertrophy of the endometrium without departure of the glands from their simple tubular form, and one of its most striking features is the onset of oedema and haemorrhage into the stroma of the endometrium. It was found that the proliferative phase could be demonstrated as early as the seventh day of the cycle. It is remarkable that within forty-eight hours of the cessation of menstrual bleeding repair of the surface epithelium is comp'ete and proliferation has developed. As I have previously shown, the oozing of blood from the endometrium at the end of the stage of proliferation sometimes causes intermenstrual bleeding, and this symptom was recorded in two cases of the series. At the time of ovulation no specific features are displayed in the endometrium except some scattering of lymphocytes from the lymph nodes of the basal layer.

The secretory phase of the endometrium, during which the glands become crenated and accumulate secretion, is restricted to the latter half of the menstrual cycle. As Schröder and I have previously observed, one of the early signs of the secretory phase is the appearance of translucent areas behind the nuclei of the cells of the glands. In the present series these areas were found on the seventeenth day, and could be demonstrated in some cases as late as the twenty-first day. They can be regarded as an early sign of the secretory phase, and they probably consist of the precursor of the mucinous secretion of the glands. Crenations are developed by the seventeenth day, although the tortuosity is not so well marked as later in the cycle. After the twenty-first day the endometrium should be considered as stationary in structure, except that later in the cycle the stroma cells which lie immedately beneath the surface epithelium become more hypertrophied. In the present series seventeen specimens of the menstruating endometrium were obtained. In all cases there is evidence of degeneration of a premenstrual endometrium; so the superficial part of the functional layer disintegrates, to be completely shed into the cavity of the uterus.

The investigations on the endometrium of the uterus indicate that after the fourteenth day of the cycle specific chánges take place in the functional layer of the endometrium, changes which are never seen at an earlier stage of the menstrual cycle. If it is assumed that these specific changes are induced by the corpus luteum which forms from the follicle which has ruptured, the time of ovulation can be deduced. On this basis it follows that the time of ovulation can roughly be determined. The specimens of the present series go to prove that the specific crenations and the bright areas in the cells of the glands are never found before about the fourteenth day, and it is not until the seventeenth day that these changes are well displayed. This method of determining the time of ovulation is in. direct, and is obviously not capable of any accuracy. On the other hand, it offers very strong confirmatory evidence in favour of the view which has already been expressed. From a study of the specimens of endometrium alone, without any knowledge of the alterations in the ovaries, one would conclude that some factor had been introduced on about the fourteenth day of the cycle which was responsible for the secretory phase of the endometrium.

Seventy specimens of endometrium were examined, some thirty of which corresponded to the time between the fourteenth and twenty-eighth days of the cycle. Without exception they showed the typical premenstrual hypertrophy of the secretory phase. Similarly, in specimens removed before the fourteenth day there was no premenstrual hypertrophy. The series is fairly large, and the results of the investigation may be taken as being typical of the changes in the normal woman. Premenstrual hypertrophy must therefore be accepted as an invariable feature of the normal menstrual cycle. Recently, Mazer ${ }^{10}$ has suggested that in cases of functional sterility premenstrual hypertrophy of the endometrium is not found, deducing from this that the corpus luteum phase of the cycle is deficient. The results obtained in my own series not only do not support this view, but are diametrically opposed to it. It is true that functional sterility was not the complaint of any of the cases of the present series, but some of the patients were married women and sterile. Personally I am very sceptical as to whether much reliance should be placed upon any investigation on premenstrual hypertrophy unless the histologist is an expert at gynaecological pathology.

\section{Anovular Bleeding}

The next point I wish to emphasize is that the large series of specimens of menstruating endometrium indicate that menstruation in women with regular menstrual cycles consists in the disintegration of a premenstrual endometrium. There was no exception to this rule. The process of menstruation in man is clearly different from the anovular cyclical bleeding of Corner's macaque monkeys. Two schools have grown up: one-which includes Robert Meyer, Schröder, and myself-maintains that the term menstruation should be restricted to what it was originally intended for-namely, cyclical uterine bleeding in women ; the other emanates from the New World, and includes Corner, Hartmann, and Novak, who postulate that cyclical uterine bleeding of any kind, whether ovular or anovular, whether seen in man or primates, is deserving of the term menstruation. The work described in this paper shows very clearly what menstruation is-namely, the disintegration of a hypertrophied premenstrual endometrium in a cycle which is essentially ovular. When the evidence accumulated by Meyer, Schröder, and myself is put before the American school their reply is "the discussion is merely a play on words" (Novak $\left.{ }^{11}\right)$, and they conveniently forget that they are responsible for the suggested modification of the definition of menstruation, with all its confus:on and implications. The situation is not without its humorous side, for Schröder and I have, as much as anyone, recorded the best example of anovular bleeding in man-namely, metropathia haemorrhagica. Neither of us, however, has ever called this form of haemorrhage menstruation, although I have pointed out that the disintegration of the endometrium in metropathia haemorrhagica is identical with that seen in normal menstruation. I have searched for other examples of anovular bleeding in human material since Corner's original paper, but it is only during the last year that I have encountered it. The cases are obviously pathological, and belong to the indeterminate group in my classification of the forms of irregular uterine haemorrhage. Much has been written in the last two years-in America-on so-called anovular bleeding in women. It is not an exaggeration to say that almost all these publications are valueless, with the evidence unreliable, discussion uncritical, and usually with the author's enthusiasm for the macaque's anovular bleeding outrunning his gynaecological discretion. Recently Novak has stated that, although he believes cyclical anovular bleeding in women to be more frequent than is generally believed, he cannot yet produce the evidence."11 A more scientific method of approach would be first to produce the evidence and afterwards to judge the frequency of this form of haemorrhage. 


\section{SUMMARX}

1. I have attempted to picture the relation between ovulation and menstruation in women who menstruate regularly with a normal rhythm. I have shown in other publications that irregular bleeding is characterized by departures from the normal relations.

2. The time relations of ovulation and menstruation have been reinvestigated with the use of the method of identifying recently ruptured follicles in the ovaries of women who give reliable histories.

3. It has been shown that ovulation is restricted to about the fourteenth day of the cycle.

4. There is some variation in the time of ovulation, but the variation is probably not more than two days from the fourteenth day.

5. A study of the condition of corpora lutea at other stages of the cycle confirms this view.

6. Indirect proof as to the time of ovulation can also be obtained by an examination of specimens of the endometrium of the uterus. It has been shown that the secretory phase of the endometrium develops after the fourteenth day of the cycle. The specific features of the secretory phase are never seen before the fourteenth day.

7. Seventeen specimens of the menstruating endometrium have been examined. In all cases there was evidence of previous premenstrual hypertrophy. In the material examined no parallel was found to the anovular cyclical bleeding of the macaque monkey.

References

${ }^{1}$ Meyer, Robert: Arch. f. Gynäk., 1911, xciii, 382.

${ }^{2}$ Meyer, Robert, and Ruge: Zentralbl. f. Gynäk. 1913, xxxvii, 50.

3 Schröder: Arch f Gynäk 1914, ci, 17.

Novak: Journ. Amer. Med. Assoc., 1916, lxvii, 1285.

5 Allen, Pratt, Newell, and Bland: Ibid., 1930, xci, 1080

- Krieger and Fosten: Quoted by Hernstein, Med. Klinik, 1933 xxvii, 899 .

7 Hartmann: Carnegie Publications, Washington, 1932, No. 433, p. 41.

${ }^{8}$ Teacher, J. H.: British Medical Journal, 1930, ii, 896.

' Correr: Journ. Amer. Med. Assoc., 1927, lxxxix, 1838.

${ }^{10}$ Mazer, C., and Zizermann, A. J.: Amer. Journ. Surg., 1932, xviii, 332.

11 Novak: British Medical Journal, 1933, ii, 553.

12 Shaw, Wilfred: Journ. Physiol., 1925, lx, No. 3. 13 Idem: Journ. Obstet. and Gynaecol. British Empire, 1929, xxxvi,
No. 1.

\section{A CONTRIBUTION TO THE GENETIC STUDY OF MENTAL DEFICIENCY}

\author{
BY
}

L. S. PENROSE, M.D.

RESEARCH MEDICAL OFFICER, ROYAL EASTERN COUNTIES' INSTITUTION, COLCHESTER

The following family history is unusual from several points of view. It records the results of the union of a brother and sister. The brother is insane and of low mentality, and the sister is certified feeble-minded. Three children were born to the sister, and the brother was almost certainly their father. The mental condition of these children is a matter of great interest, both from the genetic and from the sociological points of view. Details of the members of this incestuous family group are now given.

\section{General Family History}

The brother and sister were fifth born and eighth born, respectively, in a family of eight children. Their parents were ordinary, working-class people, and both lived to be over 80. One of the mother's sisters is said to have been subject to epilepsy, and a great-great-nephew, who is also epileptic, is certified feeble-minded. Apart from these instances we have little evidence in the family of what could be termed neuropathic traits, although a sister of the incestuous couple, the seventh born in the family, is regarded as mentally dull. This sister married a first cousin once removed (on the mother's side), and has eleven children, all of whom are said to be capable and intelligent.

\section{THE BROTHER}

$\mathrm{He}$ is now aged $\mathbf{5 4}$, and in a mental hospital suffering from general paralysis. $\mathrm{He}$ has been given a course of malaria treatment, and, while the physical condition remains fairly good, he shows a severe dementia. No definite measure of his mental capacity has been obtained, but his general intelligence is reported to have appeared subnormal before the onset of dementia. In view of the average level of intelligence among his sisters, it is improbable that his mentality was high. Unfortunately it has been impossible to trace his record at the Roman Catholic school where he was educated.

After leaving school he was employed as a stable boy, and he later drove a cab. Then he joined the Army, from which he deserted in South Africa. He worked his passage to England, and shortly afterwards began to live with the sister who was eight years his junior. The man earned his living as a general labourer at the gasworks, and the woman did some occasional charring. The couple remained together as man and wife for fifteen years, and, according to contemporary accounts, they were on very affectionate terms. They seemed to be happy and were fond of their three children, who were born during this period. The first, a male child, died at the age of $2 \frac{1}{2}$ years; there is no evidence that this child was abnormal. A year or two after the death of this child another boy was born, who is still alive. Some ten years after this, relatives of the couple discovered that the woman was again pregnant. An anonymous letter was sent to the police suggesting that the state of affairs required investigation. Two officers in plain clothes called at the flat where the couple and their son were living, only to find that they had absconded, leaving their belongings behind. Two years later they were located, living under an assumed name, in a neighbouring town; another boy had, in the meantime, been born. The man and woman were arrested and, at the Petty Sessions, were committed for trial to the Assizes. They were not legally represented. During the intervening period the woman was examined by the medical authorities, and it was decided that she was mentally defective. The man was apparently not examined from this point of view. $\mathrm{He}$ was convicted under the Punishment of Incest Act, and sentenced to sixteen months' imprisonment. A year after his release from prison he was certified insane.

\section{The Sister}

She is aged 46 and certified mentally defective. She is thin, and appears to have been poorly nourished ; she is quiet and reserved in her behaviour, and speaks clearly and connectedly. The Wassermann reaction is negative. She is occasionally liable to fits of temper, but is a diligent worker in the laundry of the institution where she is now cared for.

Although she had been educated, like her brother, at a Roman Catholic school, on admission to this institution (by an order made in court) she could not tell the number of feet in a yard, and stated that Scotland was the capital of England. She has been tested since, by standardized tests, with the following results: Binet tests (Stanford revision), 8 years 10 months ; Porteus maze test (Vineland revision), 8 years; Healy pictorial completion test, No. 1, 7 years. Her mental ratio, or intelligence quotient, is therefore roughly from 50 to 60 per cent. (according to whether we take 16 years or 14 years to be the maximum divisor).

\section{Surviving ChILdReN}

There are two surviving children, both male, aged 17 and 7 respectively. The elder is physically rather small, but healthy and active. He is quick-witted, and appears very sensible in conversation; his appearance is not very 